\title{
Malaria Seroprevalence in the Blood Donors of Malaria Endemic Regions of Northern Andhra Pradesh, India.
}

\author{
Sitalata C. ${ }^{\mathbf{1}}$, Kalyan $\mathrm{K}^{\mathbf{2 *}}$ \\ DOI: https://doi.org/10.17511/jopm.2020.i08.06
}

${ }^{1}$ C. Sitalata, Assistant Professor, Department of Pathology, Maharaja Institute of Medical Sciences, Vizianagaram, Andhra Pradesh, India.

${ }^{2 *}$ K. Kalyan, Professor, Department of Pathology, Dr. PSIMS, and RF, Gannavaram, Andhra Pradesh, India.

Introduction: Transmission of malaria through blood transfusion continues to be a major threat to safe blood transfusion practice. Transfusion-transmitted malaria occurs at an estimated rate of 0.25 cases per 1 million blood units collected. It is significantly more common in endemic areas. Aim: To study the Seroprevalence of Malaria among the blood donors in the endemic areas of Northern Andhra Pradesh. Materials and methods: The present survey was carried out at the blood bank of Maharaja institute of medical sciences, Vizianagaram. This includes the analysis of seroprevalence of Malaria in the blood donors during the period of 1 year from February 2018 to January 2019. Two ml of the blood sample was collected in the labeled pilot tube at the time of collection of blood from donor tubing of the blood bag. The serum was separated. The samples were tested for Malaria by rapid antigen detection test. Results: Out of the total of 3096 blood donors, replacement donors $(86.91 \%)$ were more in comparison to voluntary donors $(13.08 \%)$. The seroprevalence among the replacement blood donors was more compared to voluntary blood donors. Conclusion: Voluntary blood donation, increasing awareness about blood donation in the general population, selection of repeat, non-remunerated, regular voluntary blood donors and diligent donor selection, sensitive screening tests are most important to increase blood safety and prevent transmission of Malaria through blood transfusion.

Keywords: Malaria, Seroprevalence, Blood donors, Endemic zone

Corresponding Author

K. Kalyan, Professor, Department of Pathology, Dr. PSIMS, and RF, Gannavaram, Andhra Pradesh, India. Email: kotikalyan2305@gmail.com
How to Cite this Article

Sitalata C, Kalyan K. Malaria Seroprevalence in the Blood Donors of Malaria Endemic Regions of Northern Andhra Pradesh, India.. Trop J Pathol Microbiol. 2020;6(8):493-497.

Available From

https://pathology.medresearch.in/index.php/jopm/ar ticle/view/506
To Browse

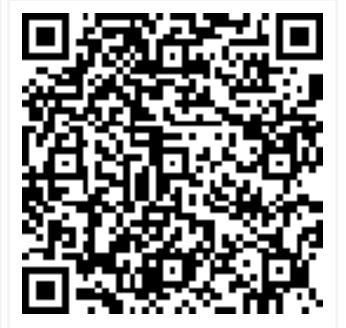

Manuscript Received 2020-11-28

Conflict of Interest No
Review Round 1 2020-12-08

Funding $\mathrm{Nil}$

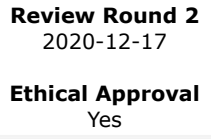

Review Round 3

Plagiarism X-checker $8 \%$
Accepted 2020-12-23

Note (c) 2020 by C. Sitalata, K. Kalyan and Published by Siddharth Health Research and Social Welfare Society. This is an Open
Access article licensed under a Creative Commons Attribution 4.0 International License https://creativecommons.org/licenses/by/4.0/ unported [CC BY 4.0]. 


\section{Introduction}

Transfusion of blood and its components is lifesaving as well as it has life-threatening hazards. With every transfusion, there is a chance of transfusion-associated problems. Vector-borne diseases like Malaria, Filariasis, Dengue are endemic in the Northern parts of Andhra Pradesh. Among all, Malaria continues to be a leading public health problem in Northern Andhra Pradesh. It constitutes about 400 million cases and 2.5 million deaths annually [1-5].

Transmission of malaria through blood transfusion is more common in endemic areas and cases are being reported in non-endemic areas too. Transfusion transmission malaria occurs at an estimated rate of 0.25 cases per 1 million blood units collected. In many establishments, Malaria screening in potential blood donors is based on Interviews. Even though there is a specific test for malaria, prevention of transmission of malaria through blood transfusion is not possible mainly because of the inability of the test to detect the antigen in the window period.

This survey aimed to access the Seroprevalence of malaria in blood donors of malaria-endemic regions of Northern Andhra Pradesh. The present study was done on voluntary and replacement donors in Maharaja institute of medical sciences.

Rapid diagnostic test kits are used for the diagnosis of malaria. Routine methods like microscopic visualization of malarial parasites in thick and thin smears are inadequate for wide-field applications. Rapid diagnostic tests detect malarial antigens using immunochromatographic methods. Other diagnostic methods available are microscopy using fluorochromes, polymerase chain reaction tests, and antibody detection by serology.

\section{Methods and Materials}

Study Area and Period: The present study was carried out at the blood bank of Maharaja institute of medical sciences, Vizianagaram from February 2019 to January 2020. The blood bank of the department of pathology, Maharaja institute of medical sciences is a licensed blood bank. It has an average collection of 4000 units of blood from healthy donors in and around Vizianagaram. It has been collecting blood from donors by undergoing campaigns and institutes, routinely screens the collector blood, and provide it to recipients in need at hospitals.
Also, they prepare different blood components including platelets and plasma.

Study design: A retrospective cross-sectional study.

Sample size: In this study, 3096 samples were collected. Out of these, 2691 samples were from replacement donors and 405 samples were from voluntary donors. These samples are collected from both the sex and from different age groups. The blood donor's history and lab test records were reviewed at the blood bank.

Inclusion criteria: All the donors were required to pass through a panel of questions on previous illnesses and medical conditions for blood donation. They should meet the eligibility criteria which consists of age between 17 to 65 years, body weight $>45 \mathrm{~kg}$, and no history of blood transfusion, hepatitis, jaundice, hypertension, and fever at the time of blood donation.

Exclusion criteria: Any donor who does not meet the eligibility criteria and also any donor having reaction during blood donation procedure was excluded from the study.

Sample collection: The samples were obtained from donors using the recommended bio-security measures. $2 \mathrm{ml}$ of the blood sample was collected in the labeled pilot tube at the time of collection blood from donor tubing of the blood bag. It is centrifuged at $3500 \mathrm{rpm}$ for 5 minutes to obtain clear nonhemolyzed serum. The test used to diagnose Malaria was the Rapid Diagnostic test - SD BIO-LINE RAPID TEST (Standard Diagnostic, INC) which is a visual, rapid, and sensitive immunoassay for the qualitative diagnosis of Malaria.

\section{Results}

Table-1 explained the seropositivity of malaria in different donor categories studied at Maharaja institute of medical sciences, Vizianagaram. Out of the 3096 blood donors, 2691 were replacement donors and 405 were voluntary donors.

Table-1: Seroprevalence of Malaria in different donors.

\begin{tabular}{|l|l|l|l|}
\hline \multicolumn{1}{|c|}{$\begin{array}{c}\text { Donor } \\
\text { Category }\end{array}$} & No. of blood units Screened & No. of Seropositive & $(\%)$ \\
\hline Voluntary & 405 & 0 & 0 \\
\hline Replacement & 2691 & 7 & 0.26 \\
\hline Total & 3096 & 7 & 0.22 \\
\hline
\end{tabular}


Out of the 3096 screened blood samples, seven units of the blood units which constitute $0.22 \%$ were positive for malarial parasites. Of the positive units, seven blood units which constitute $0.26 \%$ were from replacement donors and zero blood units from voluntary donors. Table-2 gives information about the age-wise distribution of malaria positive donors. The majority of the donor's positive donors belong to the age group of 36-45 years.

Table-2: Age-wise distribution of Malaria positive donors.

\begin{tabular}{|l|l|l|}
\hline \multicolumn{1}{|c|}{ Age Range (years) } & No of Sero-Positives & Percentage \\
\hline $18-25$ & 0 & 0 \\
\hline $26-35$ & 1 & 14.2 \\
\hline $36-45$ & 5 & 71.4 \\
\hline 46 and Above & 1 & 14.2 \\
\hline Total & 7 & 100 \\
\hline
\end{tabular}

Table- 3 shows the percentage of replacement and voluntary donors. In a study by Sonawane et al [6] at Ambajogai, out of all the blood units screened, none were positive.

Table-3: Percentage of voluntary and replacement donors in different studies.

\begin{tabular}{|l|l|l|}
\hline \multicolumn{1}{|c|}{ Authors } & Voluntary donors & Replacement donors \\
\hline Sonawane et al [6] & 1.5 & 98.5 \\
\hline Castillo et al [7] & 5.3 & 94.7 \\
\hline Singh et al [8] & 15.5 & 84.5 \\
\hline Bhattachary et al [9] & 94.6 & 5.4 \\
\hline Bruce-Chwatt et al [10] & 64.78 & 35.22 \\
\hline Present Study & 13.08 & 86.91 \\
\hline
\end{tabular}

\section{Discussion}

The overall seroprevalence of transmission of malaria through blood transfusion was $0.22 \%$. This result does not include transfusion transmission malaria during the window period, which is serological negative. This still poses a threat to blood safety in the environment. Thus, there might be a higher rate of transfusion transmission of malaria in the community.

In this study, all the positives blood units were obtained from replacement donors. This can be due to the reason that the replacement donors are less likely to express about previous exposure. Also, there was less number of voluntary donors. Several studies indicate the prevalence rates of transfusiontransmissible infections are found to be higher among replacement donors than voluntary donors.
These imply that there is a need on increasing the number of voluntary donors through creating awareness among the population. By increasing the voluntary donors, it can be ensured the safety of blood transfusion as they were at low risk.

In endemic areas, it is better to advise chemoprophylaxis for all the recipients of blood transfusion.

Elghouzzi et al [12] studied the result of the new ELISA malaria screening. The observed malaria prevalence was $0.05 \%$. Hildaf Etal [13] have reported $0.01 \%$ seropositivity among blood donors. Keshav et al 17 have reported $0.04 \%$ seropositivity among blood donors.

Interestingly, PCR analysis of 115 individuals, rejected as potential donors because they had traveled to or lived in malaria-endemic areas within the previous year, showed that none were infected with any of the Plasmodium species [7]. Thus, efficient diagnostic tests for blood donor screening need to be implemented to avoid losing valuable blood donors.

Chavan SK in their study has reported that over the last 10 years malarial infection has been negligible in the studied population. Prevalence of Malaria was low $(0.002 \%)$ with only one case being detected overall (in the year 2013). No cases of Malaria were detected in other years (2004 to 2012) [14]. Though globally malaria constitutes a big health problem in the general population, the prevalence of malaria among blood donors is low in most studies.

\section{Conclusion}

Our survey concluded that the seroprevalence of malaria was more in replacement donors than voluntary donors.

The screening of blood bank donors in endemic areas is of higher importance because of the two opposing factors in play: the scarce number of blood donors and the increased risk of disease transmission. So, it is important to increase the no. of voluntary donors who were at low risk.

\section{What does the study add to the existing knowledge?}

Based on the results, it was felt that to reduce the risk of transfusion-transmitted malaria nonremunerated repeat voluntary donor services need to be instituted. 
Extensive donor selection, sensitive screening procedures, and strict blood donation guidelines can improve blood safety. The emphasis must also be laid on voluntary risk reduction, which will require increased awareness and change in the attitude of people. With the implementation of the abovementioned strategies, it is possible to reduce the transfusion of malaria through blood transfusion.

\section{Author's contribution}

Dr. C. Sitalata: Concept, study design

Dr. K. Kalyan: Manuscript preparation

\section{Reference}

01. Fernandes H, D'souza P, D'souza P. Prevalence of transfusion transmitted infections in voluntary and replacement donors. Indian of Heamatol Blood Transfus. 2010;26(3)89-91.

doi: $10.1007 / \mathrm{s} 12288-010-0044-0$ [Crossref]

02. Elghouzzi MH, Senegas A, Steinmetz T, Guntz $P$, Barlet $V$, Assal A, et al. Multicentric evaluation of the DiaMed enzyme-linked immunosorbent assay malaria antibody test for screening of blood donors for malaria. Vox Sang. 2008;94(1)33-40.

doi: $10.1111 /$ j.1423-0410.2007.00998.x [Crossref]

03. Castillo CM, Ramírez C. Malaria screening in blood donors in Cali, Colombia. Biomedica. $2005 ; 25 ; 203-210$.

[Crossref]

04. Seed CR, Kitchen A, Davis TM. The current status and potential role of laboratory testing to prevent transfusion-transmitted malaria. Transfus Med Rev. 2005;19(3)229-240.

doi: $\quad 10.1016 / j . t m r v .2005 .02 .004 \quad$ [Crossref]

05. Rodulfo $H$, de Donato M, Quijada I, Peña A. High prevalence of malaria infection in Amazonas state, Venezuela. Rev Inst Med Trop Sao Paulo. 2007b;49(2)79-85.

doi: $10.1590 /$ s0036-46652007000200003 [Crossref]

06. Kitchen AD, Chiodini PL. Malaria and blood transfusion. Vox Sang. 2006;90(2)77-84.

doi: $10.1111 /$ j.1423-0410.2006.00733.x [Crossref]
07. Bruce-Chwatt LJ. Transfusion malaria. Bull World Health Organ. 1974;50(3-4)337-346.

[Crossref]

08. Organization WHO. New perspectives malaria diagnosis. The WHO Organization. 2000;14-15. Available at [Article] [Crossref]

09. Srikrishn A, Sitalaxmi S, Domodhar P. How safe are our safe blood donors?. Indian J Pathol Microbial. 1999;42(4)411-416.

[Crossref]

10. Singh K, Bhat S, Shastry S. Trend in seroprevalence of hepatitis $B$ virus infection among blood donors of coastal Karanataka. Indian J Infect Dev Ctries. 2009;3(5)376-379. [Crossref]

11. Bhattacharya $\mathrm{P}$, Chandra PK, Datta S, Banarjee A. Significant increase in HBV, HCV, HIV and syphilis infection among blood donors in West Bengal, Eastern India, 2004-2005, Exploratory screening reveals high frequency of occult HBV infection. World J Gastroenterol. 2013;13(27): 3730-3733.

doi: $10.3748 / w j g . v 13 . i 27.3730$ [Crossref]

12. Sharma RI, Patel KJ, Patel $H$, Dharaiya MC. Seroprevalence of transfusion transmissible infections among blood donors in tertiary care centre of Gandhinagar, Gujarat, India. Trop ] Pathol Microbiol. 2018;4(4)302-307.

Available from: [Article] [Crossref]

13. Chavan SK, Chavan KB. Seroprevalence, trend of transfusion transmittable infections and coinfections rate among blood donors at tertiary care hospital - 10 years study. Int J Res Health Sci. 2014;2(4)1014-1020.

[Crossref]

14. Irshad M, Peter S. Spectrum of viral hepatitis in thalassemic children receiving multiple blood transfusions. Indian J Gastroenterol. 2002;21(5)183-184.

[Crossref]

15. Sulhyan Kalpana R, Anvikar Arti R, Ratnaparkhi Aaditi D. Seroprevalence of transfusion transmissible infections among blood donors at a tertiary care centre in Maharashtra, India. Int J Contemp Med Res. 2017;4(9)1865-1867. [Crossref] 
16. Teklemariam Z, Mitiku $\mathrm{H}$, Weldegebreal $\mathrm{F}$. Seroprevalence and trends of transfusion transmitted infections at Harar blood bank in Harari regional state, Eastern Ethiopia- eight years retrospective study. BMC Hematol. $2018 ; 18(1) 24$.

doi: $10.1186 / \mathrm{s} 12878-018-0115-2 \quad$ [Crossref]

17. WHO African Region. Ethiopia 2006 /Regional training workshop on blood donor recruitmentpre- and post-donation counseling. 2006.

Available at [Article] [Crossref]

18. Centeral Statistics Agency. ICF MacroCalverton. Addis Ababa- Ethiopia demographic and health survey. 2011.

Available at [Article] [Crossref]
19. Talib VH, Khuana SK. Hematology for Students. 1996. 1st Ed 415-416.

[Crossref]

20. Morar MM, Pitman JP, McFarland W, Bloch EM. The contribution of unsafe blood transfusion to human immunodeficiency virus incidence in subSaharan Africa- reexamination of the $5 \%$ to $10 \%$ convention. Transfusion. 2016;6(12)31213132.

doi: $21.1111 /$ trf.13816 [Crossref] 